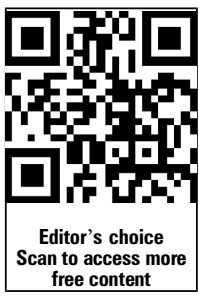

- Additional material is published online only. To view please visit the journal online (http://dx.doi.org/10.1136/ bmjspcare-2013-000508).

${ }^{1}$ North Wales Centre for Primary Care Research, Bangor University, Wrexham, UK ${ }^{2}$ The Walton Centre for Neurology and Neurosurgery, Liverpool, UK

\section{Correspondence to}

Barbara France, North Wales Centre for Primary Care Research, Bangor University, Gwenfro Building Units 5-7, Wrexham Technology Park, Wrexham LL13 7YP, UK; b.france@bangor.ac.uk

Received 18 April 2013 Revised 7 August 2013 Accepted 16 August 2013 Published Online First 18 September 2013
To cite: France $B D$, Lewis $R A$, Sharma ML, et al. BMJ Supportive \& Palliative Care 2014:4:19-29.

\title{
Cordotomy in mesothelioma-related pain: a systematic review
}

\author{
Barbara D France, ${ }^{1}$ Ruth A Lewis, ${ }^{1}$ Manohar L Sharma, ${ }^{2}$ \\ Marlise Poolman ${ }^{1}$
}

\section{ABSTRACT}

Background Cordotomy can be effective in relieving pain for patients with mesothelioma, but the evidence to support continued provision is limited. This review forms part of the Invasive Neurodestructive Procedures in Cancer Pain pilot study: The role of cordotomy in mesotheliomarelated pain in the UK.

Aim/design We report on the results of the first comprehensive systematic review of the use of cordotomy in mesothelioma-related pain, with specific reference to effectiveness in relieving pain and safety. The review was conducted according to guidelines reported in the NHS Centre for Reviews and Dissemination and the Preferred Reporting Items for Systematic Reviews and Meta-Analyses (PRISMA) guidelines for systematic reviews and meta-analyses.

Data sources 14 databases from inception to March 2012 were searched, with no limitations on language or publication type.

Results Nine studies met the inclusion criteria, all of which were case series of percutaneous cervical cordotomy (PCC) involving 160 patients. All studies demonstrated good pain relief in the majority of patients. Initial post-procedure measurements showed the greatest reduction in pain. Some side effects (headache, mirror pain, motor weakness) occurred relatively frequently but were mostly transient. Respiratory dysfunction post-PCC was rare. No deaths were directly ascribed to cordotomy.

Conclusions The available evidence is significantly limited in quantity and quality. Although it seems to suggest that cordotomy might be safe and effective in this setting, more reliable evidence is needed to aid decision making on continued provision. A national registry for cordotomy would be a valuable first step in this process.

\section{INTRODUCTION}

In the UK in 2008, 2400 people were diagnosed with mesothelioma. ${ }^{1}$ The incidence is still rising and is expected to peak around 2020. ${ }^{12}$ More patients die of mesothelioma than cervical cancer, malignant melanoma or endometrial carcinoma. ${ }^{3}$ Between 2006 and 2020, up to 30000 people will die of mesothelioma in the UK. ${ }^{3}$ Palliative care and symptom control is central to the management of patients as the disease is often associated with difficult pain syndromes and other symptoms that may respond inadequately to pharmacological approaches alone. The National Mesothelioma Framework suggested that patients should have access to services that offer cordotomy as a palliative intervention to provide relief from challenging pain syndromes. ${ }^{4}$ However, great inequity exists in the provision of services offering cordotomy; new services are being established, while others have closed (Makin, unpublished data, 2012). For a small group of patients the procedure may yield significant analgesic benefit, yet there is an unquantified associated morbidity.

There seems to be little published evidence to support continued provision and commissioning of cordotomy, a fact that is supported by the findings of Raslan et $a l^{5}$ who concluded that 'evidence needs to meet the current evidence-based standards through clinical trials.' In an attempt to consolidate all available evidence, the Invasive Neurodestructive Procedures in Cancer Pain (INPiC) pilot study was designed to focus on the use of cordotomy in mesothelioma-related pain (Makin, unpublished data, 2012). This review was conducted as part of the INPiC pilot study. This article reports on the results of the first comprehensive systematic literature review, with specific reference to safety and effectiveness of cordotomy in mesothelioma-related pain.

\section{METHODS}

This systematic review was conducted and reported according to NHS Centre for Reviews and Dissemination (CRD) Report 47 and Preferred Reporting Items for 
Systematic Reviews and Meta-Analyses (PRISMA) guidelines. ${ }^{6}{ }^{7}$ A preliminary scoping search showed a limited evidence base; the search strategy was therefore designed for sensitivity rather than specificity. A search strategy developed for Medline was adapted for 13 other databases; all were searched from inception until March 2012 (table 1). Reference lists from previous reviews and included studies were hand searched.

Inclusion criteria were as follows:

- Participants: patients with mesothelioma where the intention was to perform cordotomy (open or percutaneous) as a treatment for the control of intractable pain.

- Intervention: cordotomy: the creation of a permanent (often heat created by radiofrequency technique) lesion in the lateral spinothalamic tract in the anterolateral spinal cord.

- Control: treatment for pain using other modalities (pharmacotherapy or other neuroinvasive or neuroablative procedures).

- Outcomes: effectiveness in relieving pain and side effects.

- Study design: any, except reviews and single case reports.

There were no limits on language, year of publication or publication status. Two reviewers independently screened the titles and abstracts for relevancy. Disagreements were resolved by discussion or, if necessary, a third reviewer.

In studies that reported data on multiple diseases (including mesothelioma), only information relevant to mesothelioma was extracted. In studies where this was not possible $(\mathrm{n}=11)$, we wrote to the corresponding author and asked if they could supply us with separate data for mesothelioma patients. ${ }^{8-18}$ One author forwarded individual patient data. ${ }^{14}$

Quality assessment was performed using criteria based on the CRD quality assessment guideline for case series. ${ }^{19}$ Data were extracted into predesigned forms.

\section{Data synthesis}

Data were described using a narrative synthesis. As sample sizes of included studies were small and data

Table 1 Search strategy

\section{For Medline:}

\begin{tabular}{ll}
\hline 1 & Expcordotomyl \\
2 & chordotomy.mp \\
3 & cordotomy.mp \\
4 & tractotomy.mp \\
5 & myelotomy.mp \\
6 & 1 or 2 or 3 or 4 or 5 \\
7 & limit 6 to humans \\
\hline
\end{tabular}

Adapted for: MEDLINE in-process, EMBASE, CINAHL, PsychINFO, British Nursing Index, Cochrane Central Register of Controlled Trials, Health Technology Assessment Database, NHS Economic Evaluation Database, BIOSIS, Science Citation Index, Social Science Citation Index, Index to Scientific and Technical proceedings and System for Information on Grey Literature. potentially skewed, results were reported as median plus IQR. There were insufficient studies to assess the possibility of publication bias by funnel plots or related statistics. Outcomes were evaluated according to four follow-up periods: immediately postprocedure until 2 days, at 2 weeks, at 28 days and more than 28 days.

We included data on all patients where the intention was to perform cordotomy, meaning the patients went to theatre to have the procedure, whether they actually had a permanent (heat) lesion created or not.

The findings for 'overall pain relief at up to 2 days post-procedure' were pooled to produce a weighted average effect (meta-analysis). The analysis using a fixed-effect model (inverse-variance weighted method $)^{20}$ resulted in heterogeneity and therefore a random-effects model (DerSimonian and Laird) was also used. The analysis was consolidated using Stata V.9 and with pooled estimates of log odds converted to probability (or risk) of complete pain relief.

\section{RESULTS OF SYSTEMATIC REVIEW}

\section{The results are presented under the following headings:}

- Study selection (also refer to figure 1, table 2 and see online supplementary table S1)

- Study characteristics (see online supplementary table S1)

- Participants

- Procedure

- Quality assessment (table 3)

- Synthesis of reported outcomes (see online supplementary table S2)

- Effectiveness of cordotomy for pain relief (table 4)

- Adverse effects (table 5)

\section{Study selection}

The results of the literature searches are illustrated in figure 1 . An overview of the nine studies that met the inclusion criteria is listed in online supplementary table S1. All the studies were case series recorded between 1983 and 2011 involving a total of 160 participants (sample size ranging from 3 to 53$)^{21}{ }^{22}$ (Antrobus, unpublished data, 2011). Follow-up times ranged from 24 h post-procedure to 6 months or until death (table 2). All studies were in secondary care settings. Five of the included studies were prospective ${ }^{14} 1^{17} 2324$ (Sharma, unpublished data, 2011), three were retrospective ${ }^{22} 25$ (Antrobus, unpublished data, 2011) and one study may have been prospective, but this remains unclear. ${ }^{21}$ Two studies were unpublished (Antrobus, unpublished data, 2011, Sharma, unpublished data, 2011) (see online supplementary table S1).

\section{Study characteristics}

Participants

Participants were adults where the intention was to perform percutaneous cervical cordotomy (PCC) as a treatment for the control of severe or intractable pain 


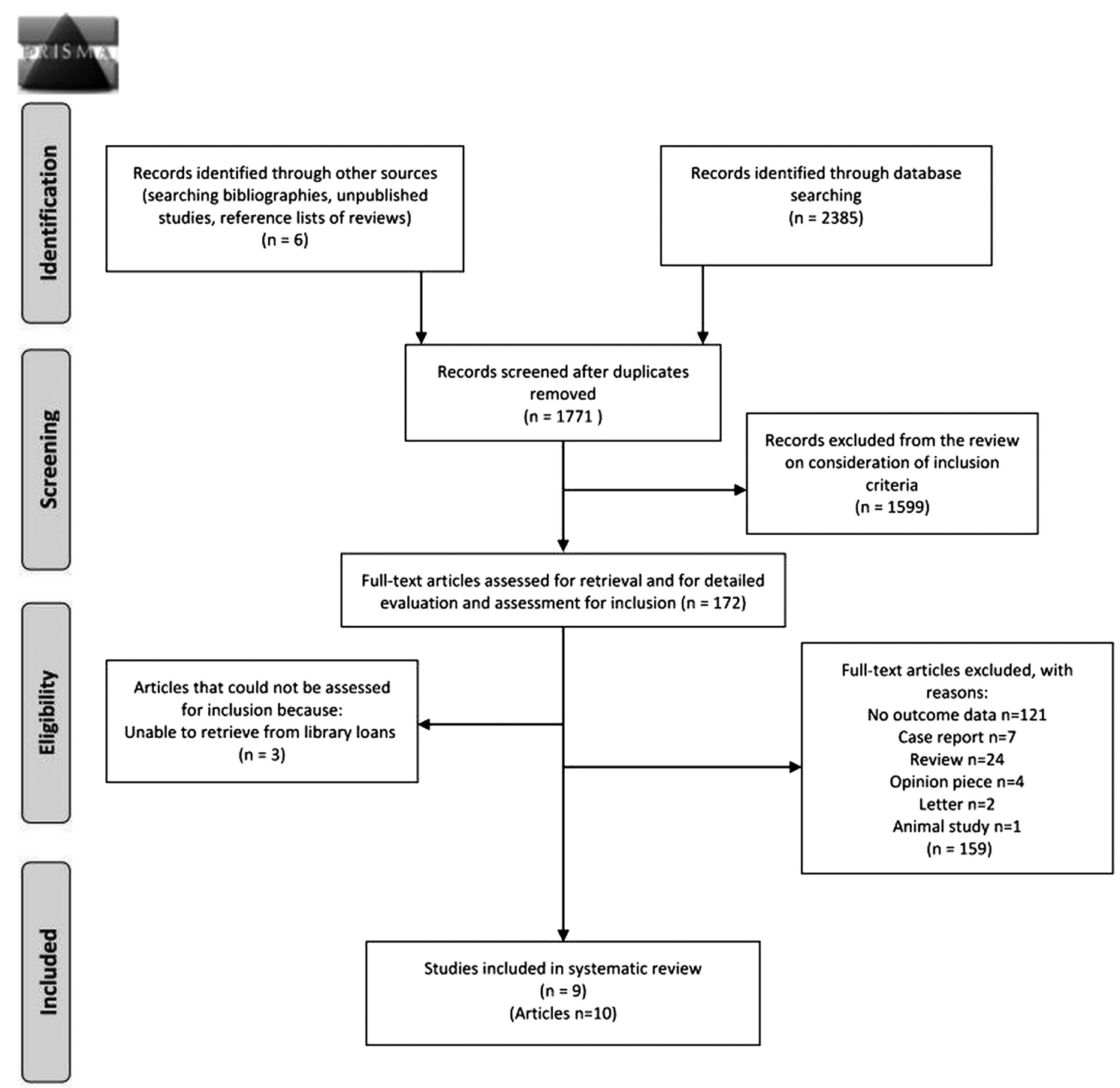

Figure 1 Preferred Reporting Items for Systematic Reviews and Meta-Analyses (PRISMA) flow chart.

due to mesothelioma (see online supplementary table S1). All studies reported on the maximum intended follow-up after the procedure (range 2-365 days). Only Jackson $e t a l^{22}$ reported detailed information regarding the stage of the disease (Butchart ${ }^{26}$ Stage 2 or above, or Tumour Node Metastasis (TNM) ${ }^{27}$ Stage 4). All studies, except Sharma (2011), reported age of participants (range 18-89 years). Six studies reported gender involving a total of 107 participants, 80/107 (74.77\%) were men and 27/107 (25.23\%) women ${ }^{14}$ 21-24 (Antrobus, unpublished data, 2011).

Pre-procedure pain descriptors were reported under four headings: site of pain, nature/type of pain, pain intensity (score) and analgesia use. All nine included studies stated that the pain was unilateral. Six studies explained more about the nature or type of pain ${ }^{14} 17222325$ (Sharma, unpublished data, 2011). Three stated that pain was intractable 1722 with Jackson $e t a l^{22}$ adding that pain was typical of chest wall involvement. Raslan(a) described pain as somatic or visceral, ${ }^{14}$ Sharma (2011) as nociceptive or mixed and Crul et $a l^{25}$ as either 'continuous somatic', 'continuous visceral', 'continuous neuropathic' or 'incident neuropathic'.

Six studies reported on pre-procedure pain intensity. Five used 11 point scales (patient self-report measures of pain ranging from no pain $=0$ to worst pain ever $=10$ ). Three of these reported a median preprocedure pain intensity score which ranged from 7.5 to $9 .^{1424} 25$ The other two reported a score for the maximum and average pain experienced in a preprocedure interval: Antrobus (2011) noted pain during the last week (worst: median $=10$, average: median=7) and Sharma (2011) reported pain in last $24 \mathrm{~h}$ (maximum: mean $=8.71$, average: mean $=6.76$ ). Nicosia $e t a l^{21}$ and Raslan(a) reported a median pain score of four on their respective five-point scales. ${ }^{14}$

Pre-procedure analgesic and opioid use was recorded in five studies ${ }^{23}$ (Antrobus, unpublished data, 2011, Sharma, unpublished data, 2011), and three reported on coanalgesic use ${ }^{22} 25$ (Antrobus, unpublished data, 2011). Almost all patients were on strong opioids (range 
Table 2 Reported outcomes (at clearly specified reporting time points)

\begin{tabular}{|c|c|c|c|c|c|}
\hline Outcome & $\begin{array}{l}\text { Immediately post-procedure } \\
\text { until } 2 \text { days }\end{array}$ & At 2 weeks & At 28 days & More than 28 days & Unclear \\
\hline Global measure of pain relief & $\begin{array}{l}\text { Antrobus } \\
\text { Kanpolat } \\
\text { Nicosia } \\
\text { Price } \\
\text { Raslan } 2005 \\
\text { Raslan } 2008 \\
\text { Sharma }\end{array}$ & Raslan 2005 & $\begin{array}{l}\text { Raslan } 2008 \\
\text { Sharma }\end{array}$ & $\begin{array}{l}\text { Kanpolat } \\
\text { Nicosia } \\
\text { Raslan } 2008\end{array}$ & \\
\hline Pain intensity & $\begin{array}{l}\text { Crul } \\
\text { Raslan } 2005 \\
\text { Raslan } 2008 \\
\text { Sharma }\end{array}$ & Raslan 2005 & $\begin{array}{l}\text { Raslan } 2008 \\
\text { Sharma }\end{array}$ & $\begin{array}{l}\text { Crul } \\
\text { Raslan } 2008\end{array}$ & \\
\hline Opioid use & $\begin{array}{l}\text { Antrobus } \\
\text { Crul } \\
\text { Jackson } \\
\text { Price }\end{array}$ & $\begin{array}{l}\text { Price } \\
\text { Raslan } 2005\end{array}$ & & $\begin{array}{l}\text { Jackson } \\
\text { Nicosia }\end{array}$ & $\begin{array}{l}\text { Kanpolat } \\
\text { Sharma }\end{array}$ \\
\hline Analgesic level & $\begin{array}{l}\text { Kanpolat } \\
\text { Price }\end{array}$ & $\begin{array}{l}\text { Price } \\
\text { Raslan } 2005\end{array}$ & & & \\
\hline Performance status & $\begin{array}{l}\text { Kanpolat } \\
\text { Raslan } 2008\end{array}$ & & & & \\
\hline Total sleeping hours & Raslan 2008 & & Raslan 2008 & Raslan 2008 & \\
\hline Patient satisfaction & Sharma & & Sharma & & \\
\hline $\begin{array}{l}\text { Adverse effects: } \\
\text { Procedure specific }\end{array}$ & $\begin{array}{l}\text { Price } \\
\text { Raslan } 2005 \\
\text { Raslan } 2008 \\
\text { Sharma }\end{array}$ & $\begin{array}{l}\text { Price } \\
\text { Raslan } 2008\end{array}$ & Sharma & & $\begin{array}{l}\text { Antrobus } \\
\text { Crul } \\
\text { Jackson } \\
\text { Kanpolat } \\
\text { Nicosia }\end{array}$ \\
\hline $\begin{array}{l}\text { Adverse effects: } \\
\text { General }\end{array}$ & Price & & & & $\begin{array}{l}\text { Jackson } \\
\text { Raslan } 2005\end{array}$ \\
\hline
\end{tabular}

98.11\% to $100 \%$ ) 222325 (Antrobus, unpublished data, 2011, Sharma, unpublished data, 2011), with doses reported in three studies (in morphine equivalents over $24 \mathrm{~h}$ ) as median $=410 \mathrm{mg},{ }^{25}$ median $=100 \mathrm{mg}^{22}$ and mean $=153.13 \mathrm{mg}$ (Sharma, unpublished data, 2011). Coanalgesic use: Crul et $a l^{25}$ noted that some patients were on neuropathic agents and Jackson $e t \mathrm{al}^{22}$ reported that 36 patients $(36 / 53,67.92 \%)$ were on morphine and coanalgesics.

Four studies used likely prognosis as one of their inclusion criteria, although none specified the criteria used to estimate prognosis ${ }^{14} 21$ (Antrobus, unpublished data, 2011, Sharma, unpublished data, 2011). Survival post-procedure was recorded in four studies (range 227-36 527 days) ${ }^{17} 2225$ (Antrobus, unpublished data, 2011).

Five studies reported performance status: four ${ }^{14} 212325$ used the Karnofsky Performance Status (KPS) Scale, where 100 is perfect health and 0 is death (median ranged from 55 to 75$)^{1425}$ and one (Antrobus, unpublished data, 2011) the Brief Pain Inventory for interference in aspects of daily life (general activity median $=9$ ). Three studies gave descriptors of respiratory function. ${ }^{172325}$

\section{Procedure}

All studies reported on PCC and none on open cordotomy. Six used X-ray control ${ }^{172122} 25$ (Antrobus, unpublished data, 2011, Sharma, unpublished data, 2011) employing the standard Lipton technique (with cervical vertebrae $[\mathrm{C}] 1 / 2$ foramen entry, lateral approach). ${ }^{28}$ Two studies used water-soluble contrast, ${ }^{17}{ }^{22}$ while others used lipid-soluble contrast. Although there were differences in the starting temperature and duration, all authors titrated the heating of the cordotomy probe to an observed effect on pain relief or sensory examination. Sedation in small doses was used in some of the studies. Three studies used CT guidance. ${ }^{1423}{ }^{24}$ Raslan(b), in his 2005 study, employed an anterior transdiscal approach at C4/5 or C5/6 level using water-soluble contrast. ${ }^{24}$ Four studies reported on staff performing or assisting in the procedure ${ }^{1424}$ (Antrobus, unpublished data, 2011, Sharma, unpublished data, 2011). All procedures were performed by a pain specialist assisted by others, including a radiographer and theatre support staff (Antrobus, unpublished data, 2011, Sharma, unpublished data, 2011). Five patients in three studies did not have heat lesions due to needle or electrode placement difficulties $^{1724}$ (Antrobus, unpublished data, 2011).

\section{Quality assessment}

Based on the quality assessment presented in table 3, the reviewers felt equal importance could be assigned to the evidence in the included studies as all had one or more limitations: loss to follow-up of more than $10 \%{ }^{17}{ }^{23}$ (Sharma, unpublished data, 2011), nonconsecutive series, ${ }^{22}$ retrospective ${ }^{22}{ }_{25}$ (Antrobus, 
Table 3 Quality assessment

\begin{tabular}{|c|c|c|c|c|c|c|c|c|c|}
\hline $\begin{array}{l}\text { Author, year } \\
\mathrm{n}=\text { number of } \\
\text { mesothelioma } \\
\text { patients }\end{array}$ & $\begin{array}{l}\text { Was this a } \\
\text { prospective } \\
\text { study? }\end{array}$ & $\begin{array}{l}\text { Are the } \\
\text { criteria for } \\
\text { inclusion } \\
\text { explicit? }\end{array}$ & $\begin{array}{l}\text { Is the study based } \\
\text { on a } \\
\text { representative } \\
\text { sample? }\end{array}$ & $\begin{array}{l}\text { Were patient } \\
\text { characteristics } \\
\text { described? }\end{array}$ & $\begin{array}{l}\text { Did all individuals } \\
\text { enter at a similar } \\
\text { point in their } \\
\text { disease } \\
\text { progression? }\end{array}$ & $\begin{array}{l}\text { Was loss to } \\
\text { follow-up } \\
<10 \% \text { ? }\end{array}$ & $\begin{array}{l}\text { Was follow-up long } \\
\text { enough for } \\
\text { important events to } \\
\text { occur? (as specified } \\
\text { by authors)* }\end{array}$ & $\begin{array}{l}\text { Were outcomes } \\
\text { assessed using } \\
\text { objective criteria } \\
\text { or was blinding } \\
\text { used?† }\end{array}$ & $\begin{array}{l}\text { If comparisons of subseries } \\
\text { are being made, was there } \\
\text { sufficient description of the } \\
\text { series and the distribution of } \\
\text { prognostic factors }\end{array}$ \\
\hline Antrobus $2011 \mathrm{n}=3$ & No & Yes & Yes & Yes & Yes & Yes & Yes & No & No subseries \\
\hline $\begin{array}{l}\text { Crul et al, } \\
n=4\end{array}$ & No & Yes & Yes & Yes & Yes & Yes & Yes & No & No subseries \\
\hline $\begin{array}{l}\text { Jackson et al, } 221999 \\
\mathrm{n}=53\end{array}$ & No & Yes & Noł & Yes & Yes & Yes & Yes & No & No subseries \\
\hline $\begin{array}{l}\text { Kanpolat et al, } \\
2002 n=19\end{array}$ & Yes & Yes & Yes & Yes & Yes & No§ & Yes & Yes & No subseries \\
\hline $\begin{array}{l}\text { Nicosia et al, } \\
1983^{* *} n=3\end{array}$ & Unclear & Yes & Yestt & Yes & Yes & Yes & Yes & No & No subseries \\
\hline $\begin{array}{l}\text { Price et } a l_{,}^{17} 2003 \\
n=32\end{array}$ & Yes & Yes & Yes & Yes & Yes & Noł‡ & Yes & Yes $\S \S$ & No subseries \\
\hline $\begin{array}{l}\text { Raslan(b), }{ }^{24} 2005 \\
n=5\end{array}$ & Yes & Yes & Yes & Yes & Yes & Yes & Yes & Yesףף & No subseries \\
\hline $\begin{array}{l}\text { Raslan(a), }{ }^{14} 2008 \\
n=24\end{array}$ & Yes & Yes & Yes & Yes & Yes & Yes & Yes & No & No subseries \\
\hline Sharma 2011 n=17 & Yes & Yes & Yes & Yes & Yes & $\mathrm{No}^{* * *}$ & Yes & No & No subseries \\
\hline
\end{tabular}

*The follow-up should be at least 4 weeks for pain relief and at least 2 weeks for adverse effects: based on the consensus opinion of cordotomy practitioners across the UK (agreed at a cordotomy registry meeting at Liverpool on 8 March 2012).


this method of data collection was used.

¥The authors could not obtain five sets of notes (out of 53 consecutive patients).

§Loss to follow-up of 19 patients $(6 / 19,31.57 \%)$ after 2 days post-PCC, with no clear reasons given as to why this happened.

qUsed an objective measure to assess analgesic level (dermatomal).

**This study has been translated for data extraction, which may have resulted in the misinterpretation of some data.

t+lt is likely that the sample is a consecutive series as they state that 20 adults came to their attention during the year 1982 . We have recorded it as such with the proviso that this remains unclear.

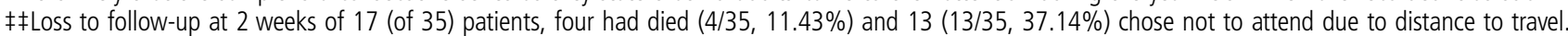

$\S \S$ Used objective measures to assess analgesic level (dermatomal)and respiratory function.

११(Used an objective measure to assess analgesic level (dermatomal).

$* * *$ Maximum loss to follow-up of five (of 17) patients at 28 days, three had died $(3 / 17,17.65 \%)$ and two were uncontactable $(2 / 17,11.76 \%)$.

PCC, percutaneous cervical cordotomy. 
unpublished data, 2011), more than 20 years old ${ }^{21}$ and included less than 10 patients ${ }^{21} 24$ (Antrobus, unpublished data, 2011).

\section{Synthesis of reported outcomes}

Effectiveness of cordotomy for pain relief

The reported outcomes are presented under the following headings (see online supplementary table S2):

- Overall pain relief (table 4)

- Pain intensity

- Analgesic interventions

- Analgesic level (dermatomal)

- Performance status

- Total sleeping hours

- Patient satisfaction (see online supplementary table S2)

Overall pain relief

Seven studies assessed overall improvement in pain immediately (and until 2 days) postprocedure $^{14} 1721^{2} 2324$ (Antrobus, unpublished data, 2011, Sharma, unpublished data, 2011).

Outcomes in six studies could be grouped into complete, partial or poor pain relief ${ }^{1417212324}$ (Antrobus, unpublished data, 2011). Complete pain relief ('complete' or 'pain free' or 'no pain') was attained in $80.22 \%$ (73/91) of patients where the intention was to perform PCC. In patients who actually received a heat lesion, complete pain relief was recorded in $84.88 \%$ (73/86). Partial pain relief ('partial' or 'partial satisfactory' or 'initial or satisfactory' or 'significant') was achieved in $14.29 \%$ (13/91) where PCC was intended (vs heat lesion $13.95 \%$ [12/86]). Poor pain relief ('poor' or 'none') was reported in 5.49\% (5/91) (heat lesion 1.16\% [1/86]). Most patients were still on some form of oral analgesia post-procedure (see online supplementary table S2), so that 'overall pain relief' reflected patients' views on the effectiveness of their full analgesic regimen.

These six studies were included in the meta-analysis (table 4), where the ordinal data were dichotomised to complete versus partial/poor pain relief ${ }^{14} \begin{array}{lllll}17 & 21 & 23 & 24\end{array}$
(Antrobus, unpublished data, 2011). In patients where PCC was intended $(n=91)$, the proportion with complete pain relief ranged from $20 \%$ to $100 \%$, with a weighted average of $75 \%$ based on a random-effects model $(95 \% \mathrm{CI}=52 \%$ to $89 \%)$. There was a moderate level of between-study heterogeneity $\left(\mathrm{I}^{2}=57 \%\right)$ which appeared to be affected by two studies that had small sample sizes and event rates ${ }^{24}$ (Antrobus, unpublished data, 2011). In patients who had heat lesions $(n=86)$, the proportion with complete pain relief ranged from $33 \%$ to $100 \%$, with a weighted average of $83 \%$ based on a fixed-effect model (95\% CI $=72 \%$ to $90 \%$; $\mathrm{I} 2=32 \%)$.

The seventh study reported pain data on a continuous scale which could not be dichotomised (Sharma, unpublished data, 2011).

At 2 weeks' follow-up, Raslan(b) reported that three patients $(3 / 5,60 \%)$ continued to have satisfactory to complete pain relief. ${ }^{24}$

Two studies reported on overall pain relief at 28 days post-procedure. Raslan(a) noted that 23 patients $(23 / 24,95.83 \%)$ had pain relief, of whom $20(83.33 \%)$ had complete pain relief. ${ }^{14}$ Sharma (2011) reported a mean of 4.45 (4='about the same' to $5=$ 'slightly better') on their seven-point 'Global Impression of Change Scale'.

At more than 28 days follow-up, Kanpolat et al ${ }^{23}$ stated that 13 patients $(13 / 13,100 \%)$ were recorded as being pain free after an average follow-up period of 5.9 months and in Nicosia et $a l^{21}$ three (3/3, 100\%) had complete pain relief at an average of 3 months follow-up. Raslan(a) reported that at 3 months follow-up 23 patients $(23 / 24,95.83 \%)$ had pain relief, of which $17(70.83 \%)$ experienced complete pain relief, and that at 6 months follow-up $22(22 / 24$, 91.67\%) had pain relief, of which eight patients $(33.33 \%)$ had complete pain relief. ${ }^{14}$

\section{Pain intensity}

Four studies reported on this outcome using either the Numerical Rating Scale (NRS) or Visual Analogue

Table 4 The results of the analysis of the probability of complete pain relief at 2 days



\footnotetext{
*The studies reported data on pain relief as ordinal data; these were dichotomised to complete pain relief versus partial or no pain relief. tInverse-variance weighted method.

$\ddagger$ DerSimonian and Laird method.
} 
Scale (VAS) ${ }^{1424} 25$ (Sharma, unpublished data, 2011). All studies reported an improvement immediately post-procedure. In three the median score ranged from zero to three (vs median pre-procedure range of 7.5-9). ${ }^{14} 2425$ The remaining study reported an average pain relief score of 0.52 in the last $24 \mathrm{~h}$ and a maximum of 0.52 (vs pre-procedure average score of 6.76 and a maximum of 8.71) (Sharma, unpublished data, 2011).

At 2 weeks' follow-up, Raslan(b) reported a mean NRS score of $3.1 .^{24}$ At 28 days, Raslan(a) noted a median overall VAS score of two. ${ }^{14}$ Sharma (2011) reported an average pain relief score of two in last $24 \mathrm{~h}$ and a maximum of 2.16 .

The two studies which reported pain intensity at more than 28 days both noted a median of two (Crul et $a l^{25}$ using NRS and Raslan[a] ${ }^{14}$ using VAS).

Analgesic interventions (including oral analgesic use and invasive procedures for pain management)

Three studies gave details on the percentage of patients who had a reduction in opioid dose ranging from $66.67 \%$ to $82.69 \%{ }^{22} 25$ (Antrobus, unpublished data, 2011).

Post-procedure opioid doses were reported in two studies. In Crul et $a l^{25}$ the median dose of morphine was $120 \mathrm{mg}$ (vs pre-procedure $410 \mathrm{mg}$ ) and Jackson et $a l^{22}$ reported the lowest daily dose as a median of $20 \mathrm{mg}$ (vs pre-procedure $100 \mathrm{mg}$ ). Price et al ${ }^{17}$ stated that 'opioid dose was halved following successful PCC 'Jackson et $a l^{22}$ reported that 43 patients (43/52, $82.69 \%$ ) had more than $50 \%$ reduction in opioid dose, and 20 (20/52, 38.46\%) stopped taking opioids altogether. Antrobus (2011) described the reduction as 'significant' with one patient $(1 / 3,33.33 \%)$ requiring 'fewer interval doses in the first $24 \mathrm{~h}$ ' and another $(1 / 3,33.33 \%)$ developed opioid toxicity immediately post-procedure. In the Crul et $a l^{25}$ study one patient $(1 / 4,25 \%)$ needed an increase in opioid dose post-procedure.

At 2 weeks' follow-up, Raslan(b) reported 'stabilization of [...] pain medication dosages or even reduction of the dose', but didn't specify the number of patients in whom this was the case. ${ }^{24}$ In the Jackson et $a l^{22}$ study, 18 patients $(18 / 52,34.62 \%)$ had recurrence of pain requiring increase in opioid dose after median of 9 weeks (range 0.71-26). Nicosia et $a l^{21}$ reported that two patients $(2 / 3,66 \%)$ required additional oral or intramuscular morphine to reach complete pain relief at an average follow-up of 3 months.

Two other studies commented on opioid use, but did not specify clear time points of follow-up. Kanpolat et $a l^{23}$ stated that in cases receiving opioid medication, doses of the drug were slowly decreased, and none of the cases received opioid treatment in their follow-up'. Sharma (2011) reported a mean percentage reduction in opioid use of $53.57 \%$ (data on 14 patients).

Two papers reported coanalgesic use: Crul et $a l^{25}$ stated that in virtually all cases non-opioids such as acetaminophen and NSAIDS were continued following successful PCC' and Jackson et $a l^{22}$ stated that 18 patients $(18 / 53,33.96 \%)$ continued on coanalgesics (vs pre-procedure $67.92 \%$ ).

The use of repeat cervical cordotomy or other invasive procedures was deemed necessary in nine patients $(9 / 160,5.63 \%)^{172122}$

Analgesic level (dermatomal)

Immediately post-procedure, Kanpolat et $a l^{23}$ noted that 15 patients $(15 / 19,78.95 \%)$ had selective pain relief (ie, segmental block) and in four patients (4/19, $21.05 \%$ ) the block involved all segments below the highest level of anaesthesia. Price et al ${ }^{17}$ stated that the maximum height of the blockade at $24 \mathrm{~h}$ ranged from C3 to T1 dermatome. This remained the same at 2 weeks. Raslan(b) reported that all three patients who had heat lesions had a recorded level of anaesthesia at T1 dermatome at 2 weeks' follow-up. ${ }^{24}$

Performance status

Kanpolat et $a l^{23}$ reported a $10 \%$ increase in the median KPS score immediately post-procedure and Raslan(a) ${ }^{14}$ found a $25 \%$ increase in the median score.

Total sleeping hours

In one study, patients' sleeping time showed an improvement immediately post-procedure (median of seven vs pre-procedure median of three), although this did decrease over the follow-up period (6 months median of five). ${ }^{14}$

\section{Patient satisfaction}

Sharma (2011) reported data on 14 patients (14/17, $82.35 \%$ ) at 2 days post-PCC. All 14 said it had been worthwhile having the procedure. At 28 days, eight patients $(8 / 9,88.89 \%)$ felt it was worthwhile.

\section{Adverse effects}

The reported outcomes are presented under the following headings (table 5):

- Procedure specific

- General

Deaths following the procedure

Most studies did not specify clear follow-up time points of specific adverse events, and three studies pooled data on patients with mesothelioma as well as other diagnoses. ${ }^{14} 1721$

Procedure specific

All included studies detailed procedure-specific adverse events, noting either events that occurred (some specifying the duration of impairment) or 


\section{Antrobus 2011 'No patient suffered neurological complication or other lasting harm'}

$\mathrm{N}=8$

$\mathrm{n}=3$

Crul et a ${ }^{25} 2005$ Mirror pain in one (1/4, 25\%) patient, transient, with minimal impact on well-being

$\mathrm{N}=43$

$\mathrm{n}=4$

Jackson et $a^{22}$

1999

$\mathrm{N}=53$

$n=53$

Dysaesthesia in two patients $(2 / 53,3.77 \%)$

Persistent motor weakness in four patients $(4 / 53,7.55 \%)$, in one graded as MRC $4 / 5$; in

three 'not regarded as severe', no data on duration of weakness, no hemiplegia or inability

Chest infection with pyrexia in two

to walk

No incontinence due to sphincter disturbance, no impotence or postural hypotension

\section{Kanpolat et $a l^{23} \quad$ Dysaesthesia in one patient $(1 / 19,5.26 \%)$}

2002

$\mathrm{N}=19$

$\mathrm{n}=19$

Nicosia et $a l^{21}$

1983

$\mathrm{N}=20$

$n=3$

POOLED DATA

Price et $\left.a\right|^{17} 2003$

$\mathrm{N}=37$

$\mathrm{n}=32$

POOLED DATA

1.6 'No

Urine retention in one $(1 / 20,5 \%)$ case resolved within 4 days after repeated catheterisations 'Weakness-ataxia' in seven cases $(7 / 20,35 \%)$ resolved spontaneously in 2-7 days

Respiratory failure in one case $(1 / 20,5 \%)$ 'needed assistance'

Postoperative hypotension in one case $(1 / 20,5 \%)$ resolved with sympathomimetics in $2-3 \mathrm{~h}$

All complications were post-surgical and temporary physiotherapy at 2 -week follow-up

'No significant change in $\mathrm{FEV}_{1.0}$ at $24 \mathrm{~h}$ or 2 weeks' (mean=1.5 L baseline, $1.5 \mathrm{~L}$ at $24 \mathrm{~h}$, $1.6 \mathrm{~L}$ at 2 weeks)

'No significant change in FVC at $24 \mathrm{~h}$ or 2 weeks' (mean $=1.9 \mathrm{~L}$ baseline, $2.0 \mathrm{~L}$ at $24 \mathrm{~h}$,

$2.14 \mathrm{~L}$ at 2 weeks), 'Improvement in FVC immediately' in 16 patients $(16 / 35,45.71 \%)$, 'mean FVC improved by $13 \%$ at 2 weeks' (mean $=1.9-2.14 \mathrm{~L}$ )

'Improvement in FVC immediately' in 16 patients, 'mean FVC had improved by 13\% at

2 weeks' (data on 18 patients)

'mean PEFR was reduced' at $24 \mathrm{~h}(315 \mathrm{l} / \mathrm{min}$ to $247 \mathrm{l} / \mathrm{min})$, 'but had returned to baseline values at 2 weeks'

'Mean partial pressures for oxygen and carbon dioxide did not alter from baseline

significantly' (mean $\mathrm{PaO}_{2}=10.3 \mathrm{kPa}$ baseline, $10.7 \mathrm{kPa}$ at $24 \mathrm{~h}$ ) (mean $\mathrm{PaCO}_{2}=5.1 \mathrm{kPa}$ baseline, $5.2 \mathrm{kPa}$ at $24 \mathrm{~h}$ )

Raslan(b) 2005 No reports of sleep-induced apnoea syndrome at $24 \mathrm{~h}$

$\mathrm{N}=8$

$\mathrm{n}=5$
Chest infection with pyrex
patients $(2 / 53,3.77 \%)$

Confusion in three
improved after $24 \mathrm{~h}$
Worsening of left ventr

of left ventricular failure following a blood transfusion in one patient $(1 / 35,2.86 \%)$

'No patients experienced postoperative pneumonia'

No complications reported
Six deaths within 2 weeks of procedure, five had successful procedures; three within 1 week, three within 2 weeks; none had a second procedure

Two died due to presumed chest infections

Two 'severely disabled by dyspnoea at rest because of pleural encasement from their tumours'

One had 'marked cachexia and a very short life expectancy due to the mesothelioma itself'

No information available regarding sequence of events

leading to death in one patient

'No mortality due to procedure'

Seven died 'due to progression of malignancy'

Four early deaths (3-14 days)

wo due to 'cerebrovascular accidents'

Iwo due to 'advanced thoracic malignancy'

No relationship between the maximum height of the

blockade as defined by pinprick testing and survival 


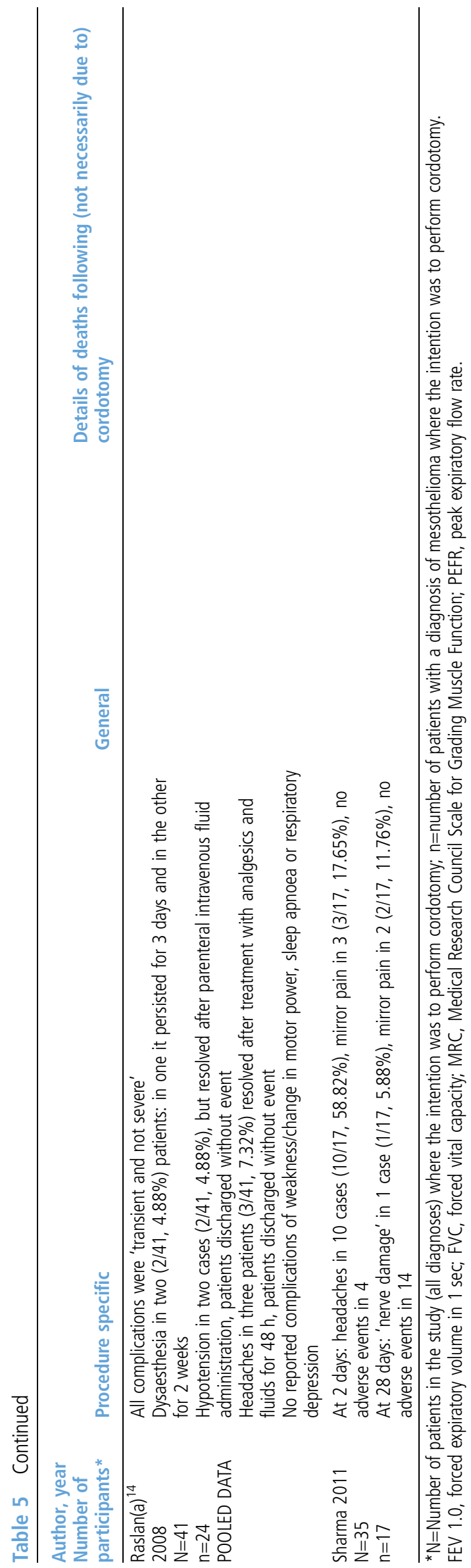

potentially significant adverse events that did not occur.

Motor weakness: Two studies ${ }^{14}$ (Antrobus, unpublished data, 2011) (44 patients) noted no patients with weakness or change in motor power but in four studies neurological deficit was recorded in 15 patients $(15 / 127,11.81 \%)^{17} 2122$ (Sharma, unpublished data, 2011). Deficit was described as 'persistent motor weakness', 'transient ipsilateral leg weakness', 'transient weakness-ataxia' and 'nerve damage'.

Dysaesthesia: Three studies reported dysaesthesia in five patients $(5 / 113,4.42 \%) .{ }^{1422}{ }^{23}$ Raslan(a) noted it was temporary. ${ }^{14}$

Mirror pain: Crul et $a l^{25}$ reported transient mirror pain in one patient $(1 / 4,25 \%)$. Sharma (2011) noted mirror pain in three patients $(3 / 17,17.65 \%)$ at 2 days post-procedure, and in two patients $(2 / 17,11.76 \%)$ at 28 days.

Urinary dysfunction/impotence: Jackson et $a l^{22}$ reported no incontinence due to sphincter disturbance and no impotence in 53 patients post-PCC. Nicosia et $a l^{21}$ noted short-lived urine retention in one case $(1 / 20,5 \%)$, which resolved after repeated catheterisations.

Respiratory dysfunction: Three studies (81 patients) reported no respiratory dysfunction post-PCC. ${ }^{14} 1724$ Nicosia et $a l^{21}$ noted respiratory failure in one case $(1 / 20,5 \%)$ who 'needed assistance'.

Headaches: Two studies described transient headaches in 13 patients $(13 / 58,22.41 \%)^{14}$ (Sharma, unpublished data, 2011).

Hypotension: One study reported no cases of postural hypotension in 53 patients. $^{22}$ Two studies noted three cases $(3 / 61,4.92 \%) .{ }^{14} 21$

\section{General}

Price et $a l^{17}$ noted short-lived confusion in three patients $(3 / 35,8.57 \%)$ and one patient $(1 / 35,2.86 \%)$ with worsening left ventricular failure following a blood transfusion. Jackson et $a l^{22}$ reported chest infection with pyrexia in two patients $(2 / 53,3.77 \%)$.

Deaths following the procedure

Three studies gave details on deaths following the procedure, but none were specifically ascribed to the procedure. ${ }^{17} 2223$

\section{DISCUSSION}

\section{Key findings}

Our review found the evidence base for the use of PCC in mesothelioma-related pain to be small. All the included studies reported case series where unilateral PCC was offered for patients suffering intractable pain due to mesothelioma. Although multiple techniques were described to perform PCC, X-ray guided techniques were most commonly used. The studies used different measures to describe effectiveness of the procedure. 
All nine case series demonstrated good pain relief in the majority of patients. This was derived from using overall pain relief measures, pain intensity scores, opioid use and dermatomal analgesic levels. Initial post-procedure measurements showed the most effect, and although the improvement in pain levels tended to lessen over time, it did not revert to pre-procedure levels. Other outcome measures also showed beneficial effect, including increased performance status and increased total sleeping hours. The majority of patients seemed to be satisfied with the procedure. A minority of patients did not have significant benefit from the procedure and required further pain blocks or repeat cordotomy.

The included studies described a range of adverse effects. Some side effects (headache, mirror pain, motor weakness) occurred relatively frequently (more than $10 \%$ of reports) but were mostly transient. Respiratory dysfunction post-PCC was rare. A number of deaths were described within 12 months of the procedure, all attributed to disease progression rather than PCC.

\section{Strengths and limitations}

The strengths of the review lie in the fact that we conducted the first comprehensive systematic review specifically on the use of cordotomy in mesothelioma-related pain. The review was not limited by either language or publication type.

The results of the review should be regarded in the context of its significant limitations, chiefly due to the low quantity and poor quality of the available evidence. All studies were case series, which are generally placed at the bottom of the evidence hierarchy. ${ }^{29} 3031$ The included studies either had small sample sizes, were retrospective and/or used a variety of outcome measures at different reporting intervals. Two of the studies are as yet unpublished. Also of note is that the three single author studies where all procedures were conducted by the author (who is likely to be an advocate of the procedure with high expectations of the procedure and carefully selected patients) might be seen as less reliable and generalisable than those with a reporting team.

Many of the authors of included studies described the reason for PCC as intractable or severe or uncontrolled pain, and some added more pain descriptors as well as prognostication to the criteria. The studies did not, however, all use directly comparable definitions of these criteria and hence the collated evidence did not give a clear indication of when the procedure should be considered, neither in terms of distinct pain parameters, nor the point in the disease trajectory or performance status of the patient.

We were unable to obtain independent patient data from eight studies, although most of these studies were at least 10 years old. ${ }^{8-10} 1213151618$

\section{CONCLUSION}

The available evidence is significantly limited in quantity and quality. Although it seems to suggest that cordotomy might be a safe and effective procedure for patients with intractable pain due to mesothelioma, in isolation it does not aid the decision making on whether continued provision of cordotomy services is warranted.

There is another consideration at play-the procedure is performed by only a handful of practitioners (Makin, unpublished data, 2012) and this skill will be lost if the weight of evidence does not tip the balance in favour of continued provision. This would be devastating for the small group of patients in whom it yields significant analgesic benefit. It is therefore imperative that good quality evidence is provided soon by welldesigned primary studies so that firm conclusions can be drawn on its effectiveness and safety.

A UK-wide registry for cordotomy could be the first step in achieving this. The comprehensive reporting will not only aid benchmarking and lead to improved patient outcomes but will also crystallise questions for further research. Parallel qualitative research into patient experiences would augment our understanding of the impact of the procedure.

Acknowledgements We thank Dr Jim Turner and Dr Belal Hannan for their practical help during this research and Richard Bailey and staff at the John Spalding Library, Wrexham Medical Institute. We also thank the authors who contributed independent patient data to the review.

Contributors Planning: BDF, RAL and MP; literature search, quality assessment, data extraction: BDF and MP;

meta-analysis: RAL; synthesis of results: BDF, MLS and MP; report writing: $\mathrm{BDF}$ and $\mathrm{MP}$; reviewing and finalising report: BDF, RAL, MLS and MP; guarantors: BDF and MP.

Funding This study was funded as part of the INPIC pilot trial by an NCRI Lung Cancer Supportive and Palliative Care Research Grant no. LCSuPaC17 (main study $£ 122229$ of which $£ 25000$ was subcontracted to Cardiff University to complete the systematic review).

Competing interests None.

Provenance and peer review Not commissioned; externally peer reviewed.

\section{REFERENCES}

1 Cancer Research UK. Mesothelioma statistics-Key Facts. http://info.cancerresearchuk.org/cancerstats/types/ Mesothelioma/?script $=$ true (accessed Jan 2012).

2 Peto J, Decarli A, La Vecchia C, et al. The European mesothelioma epidemic. Br J Cancer 1999;79:666-72.

3 Cancer Research UK. Statistics on 27 common types of cancer. http://info.cancerresearchuk.org/cancerstats/types/ (accessed Jan 2012).

4 Department of Health. Mesothelioma Framework. 2007. http:// www.dh.gov.uk/en/Publicationsandstatistics/Publications/ PublicationsPolicyAndGuidance/DH_072348 (accessed Jan 2012).

5 Raslan AM, Cetas JS, McCartney S, et al. Destructive procedures for control of cancer pain: the case for cordotomy. J Neurosurg 2011;114:155-70.

6 NHS Centre for Reviews and Dissemination. Undertaking systematic reviews of research on effectiveness: CRD's 
guidance for those carrying out or commissioning reviews. 2nd edn. York: NHS CRD, University of York, 2001.

7 Moher D, Liberati A, Tetzlaff J, et al. The PRISMA Group. Preferred reporting items for systematic reviews and meta-analyses: the PRISMA statement. PLoS Med 2009;6: e1000097.

8 Orlandini G. Percutaneous cervical cordotomy in cancer pain. Preliminary experience. Minerva Anestesiol 1991;57:141-7.

9 Stuart G, Cramond T. Role of percutaneous cervical cordotomy for pain of malignant origin. Med J Aust 1993;158:667-70.

10 Lahuerta J, Bowsher D, Lipton S, et al. Percutaneous cervical cordotomy-a review of 181 Operations on 146 patients with a study on the location of pain fibers in the C-2 spinal-cord segment of 29 cases. J Neurosurg 1994;80:975-85.

11 Nagaro T, Adachi N, Tabo E, et al. New pain following cordotomy: clinical features, mechanisms, and clinical importance. J Neurosurg 2001;95:425-31.

12 McGirt MJ, Villavicencio AT, Bulsara KR, et al. MRI-guided frameless stereotactic percutaneous cordotomy. StereotactFunctNeurosurg 2002;78:53-63.

13 Yegul I, Erhan E. Bilateral CT-guided percutaneous cordotomy for cancer pain relief. ClinRadiol 2003;58:886-9.

14 Raslan AM. Percutaneous computed tomography-guided radiofrequency ablation of upper spinal cord pain pathways for cancer-related pain. Neurosurgery 2008;62(3 Suppl 1):226-33; discussion 233-224.

15 Sanders M, Zuurmond W. Safety of unilateral and bilateral percutaneous cervical cordotomy in 80 terminally ill cancer patients. J ClinOncol 1995;13:1509-12.

16 Kanpolat Y, Ugur HC, Ayten M, et al. Computed tomography-guided percutaneous cordotomy for intractable pain in malignancy. Neurosurgery 2009;64:187-93.

17 Price C, Pounder D, Jackson M, et al. Respiratory function after unilateral percutaneous cervical cordotomy. J Pain Symptom Manage 2003;25:459-63.

18 Soud AHA. Egyptian experience in 200 percutaneous CT-guided radio-frequency cordotomy procedures. Pain Practice. 2012: 6th World Congress-World Institute of Pain, Miami Beach, USA (var.pagings). 20120212 (pp 20120144).
19 Khan KS, Terriet G, Popay J, et al. Stage II conducting the review: Phase 5 study quality assessment. In: Khan KS, Terriet G, Glanville H, et al. eds. CRD Report Number 4. York, UK: NHS Centre for Reviews and Dissemination, University of York, 2001b:11.

20 Deeks JJ, Altman DG, Bradburn MJ. Statistical methods for examining heterogeneity and combining results from several studies in meta-analysis. In: Egger M, Smith GD, Altman DG. eds. Systematic reviews in health care: meta-analysis in context. London, UK: BMJ Publishing Group. 2001:285-321.

21 Nicosia F, Pelliccia E, Dell'Amico P. Percutaneous cervical cordotomy and spinal morphine from a subcutaneous reserve in counteracting pain due to cancer. Minerva Anestesiol 1983;49:663-9.

22 Jackson MB, Pounder D, Price C, et al. Percutaneous cervical cordotomy for the control of pain in patients with pleural mesothelioma. Thorax 1999;54:238-41.

23 Kanpolat Y, Savas A, Ucar T, et al. CT-guided percutaneous selective cordotomy for treatment of intractable pain in patients with malignant pleural mesothelioma. ActaNeurochir 2002;144:595-9; discussion 599.

24 Raslan AM. Percutaneous computed tomography-guided transdiscal low cervical cordotomy for cancer pain as a method to avoid sleep apnoea. StereotactFunctNeurosurg 2005;83:159-64.

25 Crul BJP, Blok LM, van Egmond J, et al. The present role of percutaneous cervical cordotomy for the treatment of cancer pain. J Headache Pain 2005;6:24-9.

26 Butchart EG, Ashcroft T, Barnsley WC, et al. Pleuropneumonectomy in the management of diffuse malignant mesothelioma of the pleura. Thorax 1976;31:15-24.

27 Rusch VW. A proposed new international TNM staging system for malignant pleural mesothelioma. From the International Mesothelioma Interest Group. Chest 1995;108:1122-8.

28 Lipton S. Percutaneous electrical cordotomy in relief of intractable pain. Br Med J 1968;2:210-12.

29 Jabs DA. Improving the reporting of clinical case series. Am J Ophthalmo 2005;139:900-5 PMID: 15860297.

30 Barton S. Which clinical studies provide the best evidence? $\mathrm{Br}$ Med J 2000;321:255-6.

31 Sica GT. Bias in research studies. Radiology 2006;238:780-9. 